\title{
Myocardial performance index after surgical correction of ventricular septal defects
}

\author{
Yasser Baghdady, Yasser Kamel, Waleed Amar \\ Cardiology Department, Faculty of Medicine, Cairo University, Cairo, Egypt \\ Submitted: 20 February 2009 \\ Accepted: 22 May 2009 \\ Arch Med Sci 2010; 6, 3: 328-335 \\ DOI: 10.5114/aoms.2010.14251 \\ Copyright $\odot 2010$ Termedia \& Banach \\ Corresponding author: \\ Ass. Prof. Yasser Baghdady \\ Cardiology Department \\ Faculty of Medicine \\ Cairo University \\ Cairo, Egypt \\ E-mail: \\ yasserbaghdady@hotmail.com
}

\begin{abstract}
Introduction: The myocardial performance index (MPI) has been described as a non-invasive Doppler measurement of ventricular function. The aim of this study was to assess MPI following surgical correction of ventricular septal defect (VSD) and to evaluate its impact on postoperative recovery.

Material and methods: This is a prospective study involving 30 children (16 girls and 14 boys) operated on for VSD (group I). The control group (group II) consisted of 30 healthy children (age and sex matched).

Results: We found that both the right and left ventricular (RV and LV) MPI correlated significantly with the ejection fraction (EF) $(r=-0.49, p=0.006$, $r=-0.51, p=0.004$, respectively). The LV EF and the LV FS were negatively correlated, while the left and right ventricular MPI was positively correlated with the: LVEDD $(p=0.000)$, the VSD size $(p=0.000)$, and the postoperative course of the patients in terms of the duration of ventilation $(p=0.000)$, the duration of use of inotropics $(p=0.000)$ and the duration of staying in the ICU $(p=0.000)$. By linear regression, the factors that correlated with the postoperative course of VSD surgery were the RV MPI pre-surgery, MPI 2 days after surgery and the ejection fraction $(p=0.000)$.

Conclusions: Myocardial performance index is a useful index for measurement of the left and right ventricular function. It correlates significantly with the ejection fraction, fractional shortening, VSD size, and the left ventricular size. It also significantly predicts the outcome of VSD surgery.
\end{abstract}

Key words: myocardial performance index, ventricular septal defect.

\section{Introduction}

Numerous studies have shown that systolic and diastolic time intervals are closely linked to systolic and diastolic left ventricular performance. Although individual time intervals of the cardiac cycle can be easily obtained from Doppler velocity profiles as measurements of cardiac function, heart rate and load dependency have limited their clinical use [1-3]. Tei et al. [4] proposed a Doppler-derived index that is known as the myocardial performance index (MPI) for assessment of overall left ventricular function that combines systolic and diastolic time intervals. This index is defined as the sum of the isovolumetric contraction time and the isovolumetric relaxation time divided by the ejection time [5-8]. In previous studies, the index has been found to be reproducible, easily obtainable and to correlate closely with invasive measures of both systolic and diastolic function, being independent of heart rate and left ventricular 
geometry. The myocardial performance index is potentially applicable not only to the evaluation of global left ventricular function but also to the evaluation of right ventricular function [9]. Quantitative assessment of ventricular function in patients with congenital heart disease is often challenging due to distorted ventricular geometry. The myocardial performance index has been reported in adults and children as a Doppler-derived non-geometric measure of ventricular function.

Precise assessment and monitoring of myocardial performance are necessary to make appropriate therapeutic decisions in the postoperative period. An evaluation of both systolic and diastolic performance of either right or left ventricle is mandatory. The majority of children treated surgically present more or less pronounced symptoms of heart failure [10]. The form and severity of cardiac defect, injury caused by surgical trauma itself and by employment of cardiopulmonary bypass as well as dynamic changes of the haemodynamic conditions following surgical repair contribute to the postoperative changes of myocardial function [11].

The use of an extra-corporeal circulation system results in a systemic as well as local inflammatory response [12]. It has been suggested that the severity of the inflammatory processes and associated risk of heart failure development in the postoperative period correlate with previous myocardial remodelling [13]. Haemodynamic changes related to the cardiac defect induce mechanisms that enable sufficient cardiac performance under the circumstances of the pathological loading [14]. Subsequently, the myocardium undergoes remodelling [15]. In the remodelled myocardium, in addition to changes detected at either organ or tissue level, there are molecular changes that lead to increased cellular vulnerability to oxidative stress [16]. Such stress is produced by ischaemia, followed by reperfusion during the cardiopulmonary bypass [17].

The aim of the work was assessing the myocardial performance index following surgical correction of congenital ventricular septal defects and to evaluate its impact on postoperative recovery.

\section{Material and methods}

\section{Studied groups}

This prospective study involved 30 children (16 girls and 14 boys) operated on for simple ventricular septal defect (VSD) (group I). The mean age of the studied children was $24.5( \pm 2.29)$ months and they were recruited from the Paediatric and Cardiology Departments of the Faculty of Medicine, Cairo University. Oral consent was obtained from the parents of the children.
The control group (group II) consisted of 30 healthy children, referred for echocardiographic examination due to the presence of any cardiac murmur, history of chest pain or an abnormal ECG, who had normal echocardiographic findings. Oral consent was obtained from the parents of the children for the use of their echocardiographic data.

\section{Echocardiographic examination}

Complete transthoracic echocardiography including M-mode, 2-dimensional and Doppler (pulsed-wave, continuous-wave and colour) measurements was performed on all enrolled patients at rest using the Sonos 5500 ultrasound system (HP Hewlett Packard), with a $5 \mathrm{MHz}$ transducer for children.

Left ventricular (LV) end-systolic, end-diastolic and left atrial dimensions were measured in the parasternal long axis and short axis views. Ejection fraction and fractional shortening of the left ventricle were estimated according to the guidelines of the American Society of Echocardiography. Global systolic function was considered abnormal if the ejection fraction was less than $55 \%$ and the fractional shortening was below $30 \%[18,19]$.

Ventricular septal defects were identified in different windows, parasternal, subcostal and 4-chamber views where their location and size were identified. Shunt volume (restrictive or unrestrictive) was detected indirectly by measuring the dimension of the left atrium and left ventricular end diastolic dimension [20].

The mitral and tricuspid inflow velocities were recorded from the apical 4-chamber view with the pulsed-wave Doppler sample volume positioned at the tips of the mitral or tricuspid leaflets, respectively, during diastole. The left ventricular outflow velocity pattern was recorded from the apical long-axis view with the Doppler sample volume positioned just below the aortic valve, and the right ventricular outflow velocity pattern was recorded from the parasternal short axis view with the Doppler sample volume positioned just below the pulmonary valve. An electrocardiogram was simultaneously recorded with a Doppler echocardiogram in all subjects.

The interval ' $a$ ' from cessation to onset of atrioventricular valve inflow is equal to the sum of isovolumetric contraction time (ICT), ejection time, and isovolumetric relaxation time (IRT). Ejection time ' $b$ ' is derived from the duration of ventricular outflow Doppler velocity profile. The sum of ICT and IRT was obtained by subtracting ' $b$ ' from ' $a$ '. The MPI was calculated as: $(a-b) / b$ (Figure 1) [21, 22].

The MPI was evaluated on the $2^{\text {nd }}$ day, the $7^{\text {th }}$ day after surgery and at the follow-up visit one month after surgery. The MPI was calculated as previously described separately for LV and RV. 


$$
\mathrm{MPI}=\frac{a-b}{b}=\frac{(\mathrm{ICT}+\mathrm{IRT})}{\mathrm{ET}}
$$

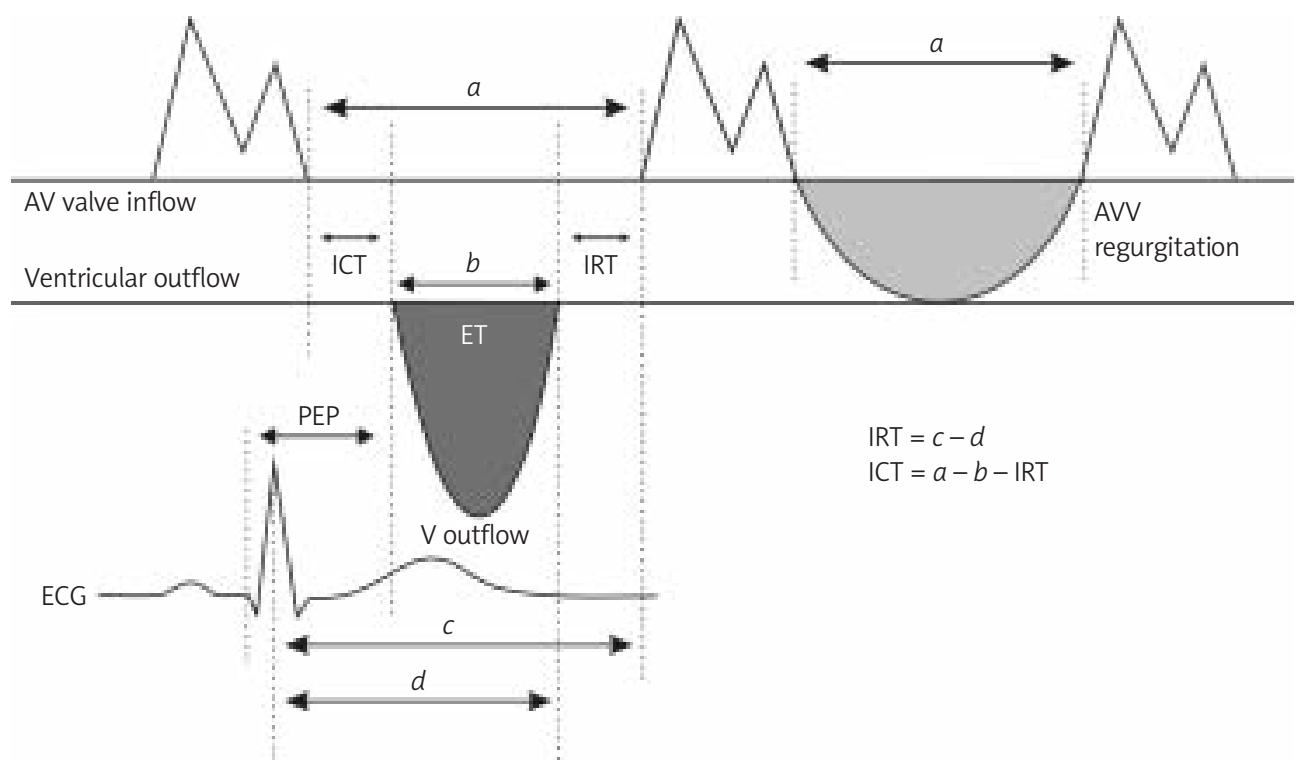

Figure 1. The MPI is calculated from the following Doppler intervals: interval " $a$ " represents the interval from cessation to onset of tricuspid valve inflow; interval " $b$ " is RV ejection time (ejection time). The MPI is the ratio of the sum of ICT and IRT divided by ejection time. The ICT and IRT can be derived as shown in equations at bottom right. Duration of tricuspid valve regurgitation can be substituted for interval " $a$ "

$A V$ - atrioventricular, AVV - atrioventricular valve, ECG - electrocardiogram, $V$-ventricular

\section{Postoperative course}

We also analysed the potential association between the size and severity of VSD defect, myocardial performance and postoperative course. Ventricular septal defect severity was defined based on the pressure gradient between RV and LV across the ventricular septum calculated prior to surgery.

The postoperative course was defined based on assisted ventilation time, inotropic support time and intensive care unit stay time. These parameters were correlated with the MPI value evaluated on the $2^{\text {nd }}$ day after surgery.

\section{Results}

\section{Healthy children}

The LV and RV dimensions, shortening fraction, PAP, LVMPI and RVMPI values in the healthy children are outlined in Table I and their results were found to be within the normal ranges.

As regards the contractile indices we found that the ejection and fractional shortening were significantly correlated $(r=0.98, p=0.000)$; also there was a significant negative correlation between the ejection fraction and fractional shortening and the RV MPI $(r=-0.49, p=0.006)$ and the LV MPI $(r=-0.51, p=0.004)$.

\section{Children with ventricular septal defect}

The LV and RV dimensions, shortening fraction, PAP and VSD size in $\mathrm{mm}$ in group II are outlined in Table II.

As regards the contractile indices there was a significant negative correlation between the ejection fraction and fractional shortening in the preoperative echocardiogram and the preoperative

Table I. General characteristics of the control group (showing the age in months, the right and left ventricular MPI, the left ventricular end-diastolic dimensions, the fractional shortening, the size of the right ventricle and the pulmonary artery pressure)

\begin{tabular}{|lccccccc|}
\hline Number 30 & Age & RV MPI & LV MPI & LVEDD & FS [\%] & RV [mm] & PAP \\
\hline Range & $20-40$ & $31-32$ & $32-34$ & $2.9-3.1$ & $28-38$ & $1.15-1.3$ & $21-29$ \\
\hline Mean & 32.16 & 0.315 & 0.332 & 3.013 & 32.16 & 1.220 & 25.66 \\
\hline Standard deviation & 5.31 & 0.005 & 0.005 & 0.007 & 2.001 & 0.237 & 1.935 \\
\hline
\end{tabular}


Table II. General characteristics of the patient group (showing the age in months, the left ventricular diastolic dimensions, the fractional shortening, the right ventricular size in $\mathrm{mm}$, the pulmonary artery pressure and the size of the ventricular septal defect)

\begin{tabular}{|lccccccc|}
\hline Number 30 & Age & LVEDD & FS [\%] & RV [mm] & PAP & VSD [mm] \\
\hline Range & $22-28$ & $3.1-3.7$ & $25-31$ & $1.3-1.8$ & $40-56$ & $6-10$ \\
\hline Mean & 24.56 & 3.346 & 27.26 & 1.513 & 49.03 & 8.13 \\
\hline Standard deviation & 2.299 & 0.1547 & 1.760 & 0.1357 & 5.027 & 0.937 \\
\hline
\end{tabular}

Table III. The MPI values (both RV and LV) over the 1-month postoperative follow-up (days 2, 7 and after 1 month)

\begin{tabular}{|lcccccc|}
\hline Number 30 & RV MPI d2 & RV MPI d7 & RV MPI 1m & LV MPI d2 & LV MPI d7 & LV MPI 1m \\
\hline Range & $0.42-0.51$ & $0.37-0.40$ & $0.31-0.32$ & $0.45-0.58$ & $0.36-0.41$ & $0.32-0.34$ \\
\hline Mean & 0.467 & 0.388 & 0.316 & 0.491 & 0.374 & 0.332 \\
\hline Standard deviation & 0.020 & 0.009 & 0.004 & 0.0364 & 0.138 & 0.005 \\
\hline
\end{tabular}

left and right ventricular MPI ( $p=0.004$ and 0.006, respectively) and the postoperative ejection fraction and fractional shortening and the postoperative right and left MPI, at 1 month follow-up ( $p=0.004$ and 0.005 , respectively).

The results of sequential LV and RV MPI measurements in children operated on for VSD are listed in Table III. In children operated on for VSD, on the $2^{\text {nd }}$ day after surgery a significant elevation of both RV MPI and LV MPI was observed.

Values of RV MPI and LV MPI were significantly higher in the patient group than in the control group, especially on the $2^{\text {nd }}$ and $7^{\text {th }}$ postoperative days $(p=0.000)$. This difference disappeared at 1 month $(p=0.3)$ [NS] between controls and patients 1 month post-operation, for both LV and RV MPI.

The regression of LV and RV MPI showed a significant decrease over the 1-month period (ANOVA $p=0.000$ ) (Figure 2).

\section{Correlations}

The LV EF and the LV FS were negatively correlated, while the left and right ventricular MPI

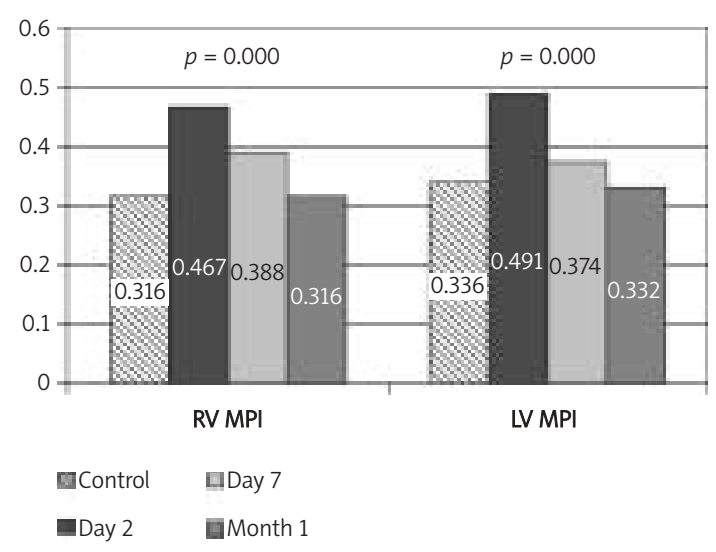

Figure 2. RV and LV MPI in the control group and patients' postoperative MPI over the 1-month period was positively correlated with the: LVEDD $(p=0.000)$, the VSD size $(p=0.000)$, and the postoperative course of the patients in terms of the duration of ventilation $(p=0.000)$, the duration of use of inotropics $(p=0.000)$ and the duration of staying in the ICU ( $p=0.000)$ (Table IV, Figures 3-6).

By linear regression, the factors that correlated with the postoperative course of VSD, in terms of ICU admission, the duration of inotropics and the duration of ventilation, were the RV MPI pre-surgery, MPI 2 days after surgery and the ejection fraction (Figure 7).

\section{Discussion}

The myocardial performance index (MPI) has been described as a non-invasive Doppler measurement of ventricular function [4, 6, 8, 23, 24, 34, 35].

The $\mathrm{MPI}$ is a ratio between the sum of isovolumic time intervals, namely, isovolumic contraction time (ICT) and isovolumic relaxation time (IRT), and ejection time. These intervals can be easily obtained by routine Doppler techniques during a standard echocardiographic examination with excellent inter- and intra-observer reproducibility [25-28, 36].

Because this index is a ratio of time intervals, it is not limited by the geometric shape of the ventricle and has been shown to be independent of heart rate $[2,8,37]$. The MPI has been shown to

Table IV. Postoperative course of the patient population, showing the ICU duration of stay of the patients, the duration the patients were ventilated in the ICU and the duration of inotropic infusion

\begin{tabular}{|lc|}
\hline ICU stay & $2.6 \pm 0.5$ days \\
\hline Duration of ventilation & $5.5 \pm 1.1 \mathrm{~h}$ \\
\hline Duration of inotropic infusion & $2.6 \pm 0.5$ days \\
\hline
\end{tabular}




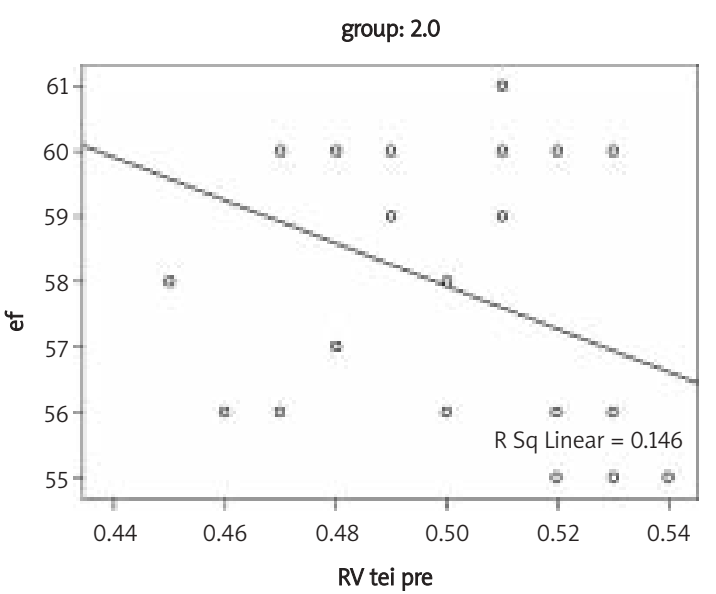

Figure 3. Shows the significant negative correlation between the ejection fraction and RV MPI $(r=-0.382$, $p=0.037)$

group: 2.0

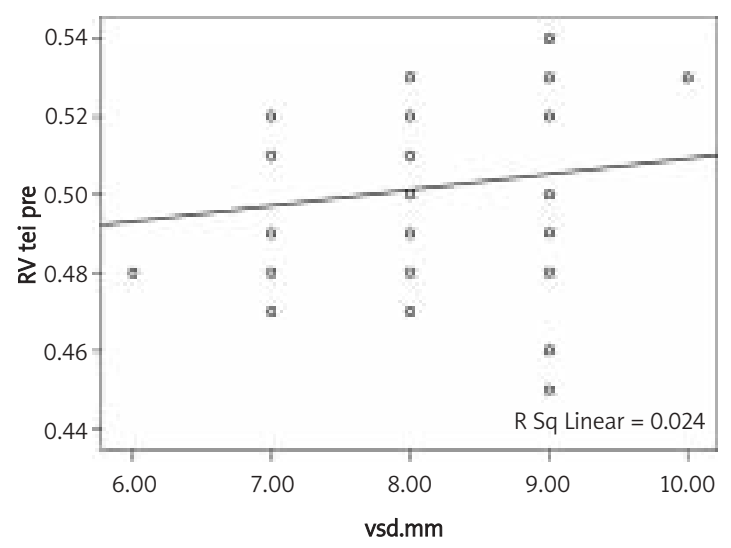

Figure 5. Significant positive correlation between the VSD size and RV MPI $(r=0.3, p=0.05)$

correlate well with other invasive and non-invasive measures of left ventricular function in adults [10, 38, 39].

In addition, studies in paediatric and adult patients have demonstrated that this index can quantitatively assess right ventricular (RV) dysfunction [27, 28, 40, 41].

In this study we found that all contractile indices, ejection fraction, fractional shortening, and both the right and left ventricular MPI are significantly correlated with the severity of the ventricular septal defect, in terms of size of the VSD and the left ventricular dimensions, and can give a good indication of the postoperative recovery of the patients after surgical closure. Thus, these indices give us a good indication about the dysfunction, in the right and left ventricles, that results from the VSD shunt.

By linear regression we also found that the RV MPI (preoperative and immediately after surgery) and the ejection fraction are the factors that most

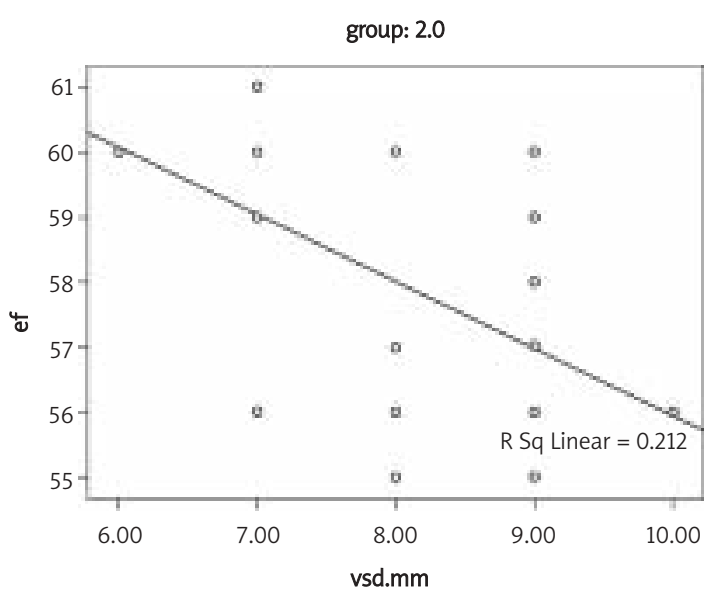

Figure 4. Significant negative correlation between the ejection fraction and VSD size $(r=-0.776$, $p=0.000)$

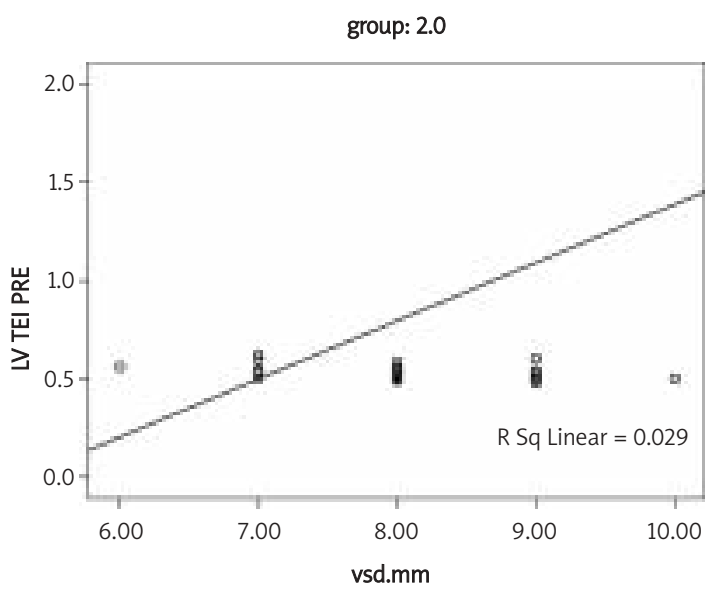

Figure 6. The highly significant correlation between LV MPI and the VSD size $(r=0.37, p=0.04)$

significantly affect the postoperative course of surgery for VSD. This is an important finding, since estimation of RV function by traditional methods is hampered by its geometric shape. Thus, using this method, early identification of RV dysfunction can be made.

The duration of postoperative ICU stays places a considerable burden on the resources of the institution. Nonetheless, despite the magnitude of the problem of the long stay in children after cardiac surgery, a detailed assessment of the specific factors that predict and necessitate prolonged intensive care stay after surgery for heart disease in children is lacking.

This study indicates that RV and LV MPI following closure of ventricular septal defects impacts upon recovery time. It follows, therefore, that perioperative assessment of MPI correlates with recovery time and that consideration of this measurement in conjunction with the intended 
operative procedure before scheduling operations may facilitate bed turnover. When ICU bed availability is an issue, children with complex chronic medical conditions including those with abnormal MPI should be electively scheduled for surgery in a series rather than parallel.

Cardiac output is a commonly used parameter in the postoperative period. However, preload, afterload, myocardial contractility and heart rate all affect this index; thus its value in the assessment of functional status of the myocardium is very limited. Theoretically MPI meets the criteria of a method capable of adequately evaluating myocardial performance.

In the examined group of healthy children, the small deviation of the results and particularly the narrow range of the MPI value confidence interval and the high level of consistency with data found in the literature confirm that the control group adequately reflected population data [32].

In the case of almost equal pressures in both cardiac ventricles, the RV is exposed to a significant pressure overload that induces hypertrophy and remodelling of the myocardium $[33,42]$.

Such a ventricle becomes particularly vulnerable to injuries related to the cardiopulmonary bypass. It leads to RV dysfunction disclosed by increased RV MPI. Postoperative course (catecholamine administration time, intubation time as well as ICU stay) correlated significantly with the index value calculated on the $2^{\text {nd }}$ day following surgery. The standard parameters of cardiac output were poor predictors of the postoperative course in our study.

This study documented the high usefulness of $\mathrm{MPI}$ measurements for the assessment of ventricular function, especially that of RV, which, if decreased, often leads to serious clinical problems in the postoperative period.

In conclusion, MPI is a useful index for measurement of the left and right ventricular function. It correlates significantly with the ejection fraction, fractional shortening, VSD size, and the left ventricular size. The right and left ventricular MPI values are significantly elevated immediately post-closure of the VSD, and over a 1-month period they normalize to be comparable with the values of the control group. The RV preoperative MPI and the immediate postoperative MPI also significantly correlate with the postoperative course of the surgery and are strongly correlated with the duration of ICU stay, the duration of ventilation and the duration of inotropic use.

\section{Limitations}

The lack of surgical data, intraoperatively, was a limitation of the study and in itself could have affected the postoperative recovery. Larger scale trials with a larger number of patients will be needed to fully validate our trial.

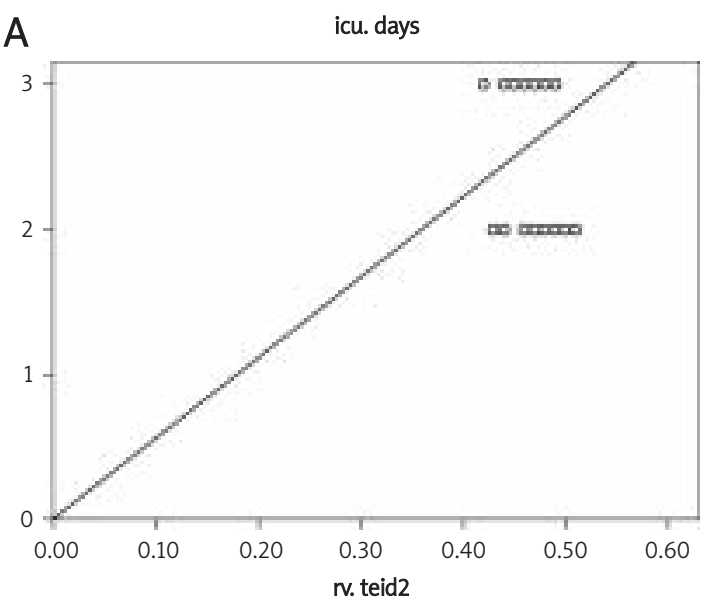

\section{B vent. day}

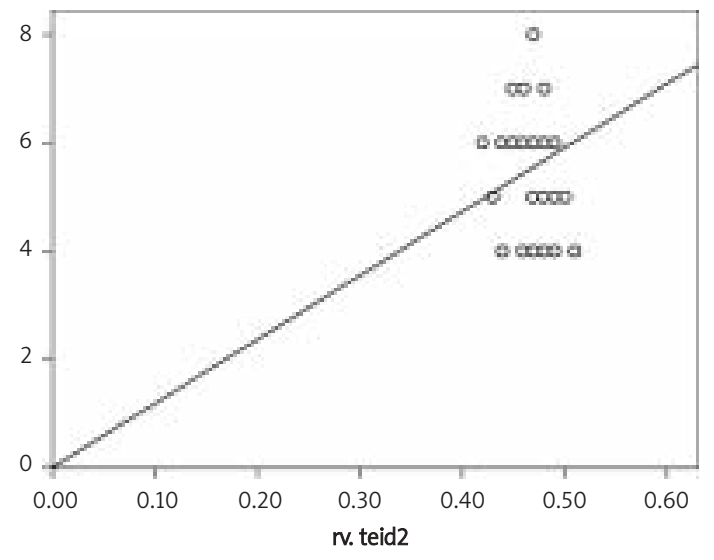

C day. inot

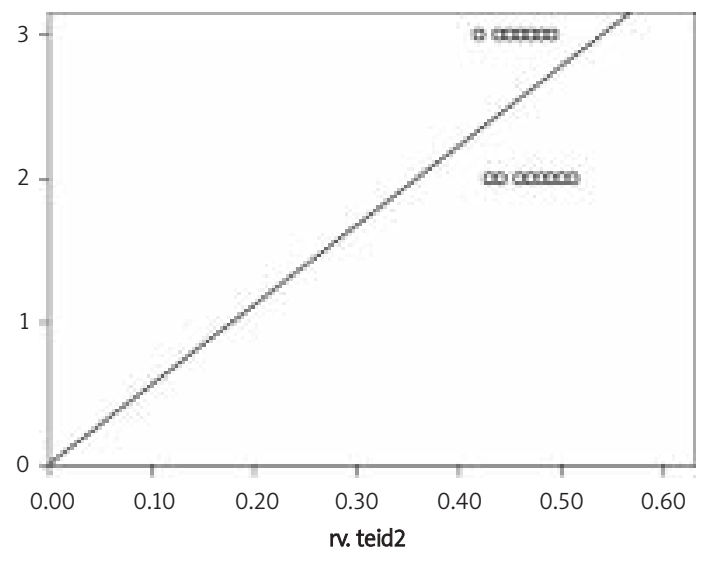

Figure 7. Linear regression analysis showing a significant correlation $(p=0.000)$ between RV MPI 2 days after surgery and the postoperative course of VSD surgery in terms of days of ICU admission, duration of ventilation and duration of inotropic administration (A, B and C, respectively) 


\section{References}

1. Burwash IG, Otto CM, Pearlman AS. Use of Dopplerderived left ventricular time intervals for noninvasive assessment of systolic function. Am J Cardiol 1993; 72: 1331-3.

2. Weissler AM. The heart in heart failure. Ann Intern Med 1968; 69: 929-40.

3. Weissler AM, Peeler RG, Roehll WH Jr. Relationships between left ventricular ejection time, stroke volume, and heart rate in normal individuals and patients with cardiovascular disease. Am Heart J 1961; 62: 367-78.

4. Tei C. New noninvasive index for combined systolic and diastolic ventricular function. J Cardiol 1995; 26: 135-6.

5. Bruch C, Schmermund A, Marin D, et al. Tei index in patients with mild-to-moderate congestive heart failure. Eur Heart J 2000; 21: 1888-95.

6. Dujardin KS, Tei C, Yeo TC, et al. Prognostic value of a Doppler index combining systolic and diastolic performance in idiopathic-dilated cardiomyopathy. Am J Cardiol 1998; 82: 1071-6.

7. Eidem BW, O'Leary PW, Tei C, Seward JB. Usefulness of the myocardial performance index for assessing right ventricular function in congenital heart disease. Am J Cardiol 2000; 86: 654-8.

8. Yeo TC, Dujardin KS, Tei C, Mahoney MD, Seward JB. Value of a Doppler-derived index combining systolic and diastolic time intervals in predicting outcome in primary pulmonary hypertension. Am J Cardiol 1998; 81: 1157-61.

9. Eto G, Ishii M, Tei C, et al. Assessment of global left ventricular function in normal children and in children with dilated cardiomyopathy. J Am Soc Echocardiogr 1999; 12: 1058-64.

10. Hammer S, Loeff M, Reichenspurner $\mathrm{H}$, et al. Effect of cardiopulmonary bypass on myocardial function, damage and inflammation after cardiac surgery in newborns and children. Thorac Cardiov Surg 2001; 49: 349-54.

11. Shaddy R. Pediatric heart failure. Taylor \& Francis 2005.

12. Edmunds LH Jr. Inflammatory response to cardiopulmonary bypass. Ann Thorac Surg 1998; 66: S12-6.

13. Modi P, Suleiman MS, Reeves BC, et al. Basal metabolic state of hearts of patients with congenital heart disease: the effects of cyanosis, age, and pathology. Ann Thorac Surg 2004; 78: 1710-6.

14. Lewartowski B. Zmiany fenotypu komórkowego w przeroście i niewydolności serca [Polish]. Kardiol Pol 2000; 53 (supl. III): 33-45.

15. Szyszka A. Przebudowa serca [Polish]. Via Medica, Gdańsk 2002.

16. Dhalla AK, Hill MF, Singal PK. Role of oxidative stress in transition of hypertrophy to heart failure. J Am Coll Cardiol 1996; 28: 506-14.

17. Mavroidis C, Backer CL. Pediatric cardiac surgery. Mosby 1994.

18. Schiller NB, Shah PM, Crawford M, et al. Recommendations for quantitation of the left ventricle by twodimensional echocardiography. J Am Soc Echocardiogr 1989; 2: 358-67

19. Otto CM. In: Otto CM (eds.) Textbook of clinical echocardiography. Philadelphia: WB Saunders 2000; 10.

20. Kimball TR, Daniels SR, Meyer RA. Relation of symptoms to contractility and defect size in infants with ventricular septal defect. Am J Cardiol 1991; 67: 1097-102.

21. Harada K, Tamura M, Toyono M, Yasuoka K. Comparison of the right ventricular Tei index by tissue Doppler imaging to that obtained by pulsed Doppler in children without heart disease. Am J Cardiol 2002; 90: 566-9.
22. Tei C, Nishimura RA, Seward JB, Tajik AJ. Noninvasive Doppler- derived myocardial performance index: correlation with simultaneous measurements of cardiac catheterization measurements. J Am Soc Echocardiogr 1997; 10: 169-78.

23. Tei C, Ling LH, Hodge DO, et al. New index of combined systolic and diastolic myocardial performance: a simple and reproducible measure of cardiac function - a study in normals and dilated cardiomyopathy. J Cardiol 1995; 26: 357-66.

24. Tei C, Dujardin KS, Hodge DO, Kyle RA, Tajik AJ, Seward JB. Doppler index combining systolic and diastolic myocardial performance: clinical value in cardiac amyloidosis. J Am Coll Cardiol 1996; 28: 658-64.

25. Tajik AJ, Seward JB, Hagler DJ, Mair DD, Lei JT. Twodimensional real-time ultrasonic imaging of the heart and great vessels: technique, image orientation, structure identification, and validation. Mayo Clin Proc 1978; 53: 271-303.

26. Nishimura RA, Miller FA Jr, Callahan MJ, Benassi RC, Seward JB, Tajik AJ. Doppler echocardiography: theory, instrumentation, technique, and application. Mayo Clin Proc 1985; 60: 321-43.

27. Eidem BW, Tei C, O'Leary PW, Cetta F, Seward JB. Nongeometric quantitative assessment of right and left ventricular function: myocardial performance index in normal children and patients with Ebstein anomaly. J Am Soc Echocardiogr 1998; 11: 849-56.

28. Tei C, Dujardin KS, Hodge DO, et al. Doppler echocardiographic index for assessment of global right ventricular function. J Am Soc Echocardiogr 1996; 9: 838-47.

29. Chang AC, Hanley FL, Wessel D (eds). Pediatric cardiac intensive care. Baltimore Williams \& Wilkins, 1999.

30. Aylin P, Alves B, Best N, et al. Comparison of UK paediatric cardiac surgical performance by analysis of routinely collected data 1984-96: Was Bristol an outlier? Lancet 2001; 358: 181-7.

31. Stark J, Gallivan S, Davis K, et al. Assessment of mortality rates for congenital heart defects and surgeons performance. Ann Thorac Surg 2001; 72: 171-5.

32. Ishii M, Eto G, Tei C, et al. Quantitation of the global right ventricular function in children with normal heart and congenital heart disease: a right ventricular myocardial performance index. Pediatr Cardiol 2000; 21: 416-21.

33. Mavroidis C, Backer CL. Pediatric cardiac surgery. Mosby 1994.

34. Zhang YQ, Sun K, Zhu SL, et al. Doppler myocardial performance index in assessment of ventricular function in children with single ventricles World J Pediatr 2008; 4: 109-13.

35. Azevedo VM, Albanesi Filho FM, Santos MA, Castier MB, et al. Is myocardial performance index an independent echocardiographic marker of death in children with idiopathic dilated cardiomyopathy? Clin Cardiol 2008; 31: 424-30.

36. Uluçay A, Tatli E. Myocardial performance index [Turkish]. Anadolu Kardiyol Derg 2008; 8: 143-8.

37. Yilmaz A, Yalta K, Turgut OO, et al. Comparison of myocardial performance index versus ratio of isovolumic contraction time/ejection time in left ventricular systolic dysfunction. Adv Ther 2007; 24: 1061-7.

38. Dagdelen S, Eren N, Karabulut H, Caglar N. Importance of the index of myocardial performance in evaluation of left ventricular function. Echocardiography 2002; 19: 273-8.

39. Turhan H, Yasar AS, Yagmur J, Kurtoglu E, Yetkin E. The impact of metabolic syndrome on left ventricular function: Evaluated by using the index of myocardial performance. Int J Cardiol 2009; 132: 382-6. 
40. Yilmaz R, Gür $M$, Demirbağ R. Is the myocardial performance index a reliable parameter in patients with restrictive filling pattern? Anadolu Kardiyol Derg 2006; 6: 221-8.

41. Karnati PK, El-Hajjar M, Torosoff M, Fein SA. Myocardial performance index correlates with right ventricular ejection fraction measured by nuclear ventriculography. Echocardiography 2008; 25: 381-5.

42. Patel N, Mills JF, Cheung MM. Use of the myocardial performance index to assess right ventricular function in infants with pulmonary hypertension. Pediatr Cardiol 2009; 30: 133-7. 